\title{
Mechanistic concepts in X inactivation underlying dosage compensation in mammals
}

\author{
M Leeb ${ }^{1}$ and A Wutz ${ }^{2}$ \\ ${ }^{1}$ Research Institute of Molecular Pathology, Vienna, Austria and ${ }^{2}$ Research Institute of Molecular Pathology, Wellcome Trust Centre for \\ Stem Cell Research, Cambridge, UK
}

\begin{abstract}
Mammals inactivate one of the two female $X$ chromosomes to compensate for the unequal copy number of $X$-linked genes between males and females. This process of $X$ inactivation entails the silencing of one $X$ chromosome in a developmentally regulated manner. In this work, we review recent findings in $X$ inactivation and discuss how these advance the mechanistic understanding. Recent results provide an insight how the cell counts and chooses the appropriate number of $\mathrm{X}$ chromosomes to inactivate, how chromosome-wide gene repression is coordinated and
\end{abstract}

how a stable inactive $X$ chromosome is established. Key components of this complex regulatory system have now been identified and provide entry points for understanding epigenetic regulation in mammals. A majority of the data has been obtained from studying mice. It is presently not clear how general these findings can be applied to other mammalian species. We try to assess this aspect from data, which has become available.

Heredity (2010) 105, 64-70; doi:10.1038/hdy.2009.181; published online 13 January 2010

Keywords: X inactivation; dosage compensation; Xist; Oct4; SATB1; SmcHD1

\section{Introduction}

In mammals one of the two $X$ chromosomes is transcriptionally silenced during early female development. Thereby, either the paternally or the maternally inherited $\mathrm{X}$ chromosome can be inactivated randomly making the developing female embryo a genetic mosaic of cells with opposite $X$ inactivation patterns. The prospect of identifying one $X$ chromosome among all DNA within the nucleus seems to be outside the domain explained by current knowledge and stretches the imagination of molecular biologists. For random $X$ inactivation, a particular system has evolved that relies on the large non-coding Xist RNA that is expressed from and localizes specifically to the inactive $X$ chromosome (Xi). Xist expression is controlled by a mechanism that ensures that one $X$ chromosome remains active in a diploid cell. Regulation involves sequences around the Xist gene, which make up the complex genetic locus of the $\mathrm{X}$ inactivation center (Xic). Xist RNA has been identified in human (Brown et al., 1991) and mouse (Borsani et al., 1991; Brockdorff et al., 1991) and is apparently conserved among placental mammals (Nesterova et al., 2001; Chureau et al., 2002). Xist has not been detected in marsupials or the more distant vertebrates (Duret et al., 2006). Presently, it is thought that the mammalian Xist gene may have been derived from a protein-coding gene, $\operatorname{Ln} x 3$ (Duret et al., 2006), in a process that involved the insertion of transposable

Correspondence: Dr A Wutz, Research Institute of Molecular Pathology, Wellcome Trust Centre for Stem Cell Research, Tennis Court Road, Cambridge CB2 1OR, UK.

E-mail:aw512@cam.ac.uk

Received 15 September 2009; revised 9 November 2009; accepted 12

November 2009; published online 13 January 2010 elements (Elisaphenko et al., 2008). Interestingly, the genomic region around the Xic shows different arrangements in placental mammals and marsupials and is autosomal in monotremes (reviewed in Deakin et al., 2009). The Xic region has undergone repeated genetic rearrangements during the evolution of mammals. In marsupials dosage compensation is achieved by inactivation of the paternally inherited $X$ chromosome (Graves, 1996; Koina et al., 2009). As marsupial Xist has not been identified it is likely that an alternative mechanism of imprinted $X$ inactivation exists.

In mice, Xist RNA forms a domain over the non-genic chromatin of the core of the $X$ chromosome territory (Chaumeil et al., 2006). Also on the human Xi XIST seems to overlap the central region of the chromosome territory, which contains mostly genomic repeats (Clemson et al., 2006). This indicates that the primary targets of Xist are not genes but sequences in the non-genic regions of the $X$ chromosome. On the $X i$ genes are positioned at the periphery of the Xist domain irrespective if they are silenced or not (Clemson et al., 2006). The situation on the $\mathrm{Xi}$ is complex. A number of genes on the human $\mathrm{Xi}$ and $\mathrm{a}$ few genes on the mouse $X_{i}$ escape gene silencing and are expressed from the $\mathrm{Xi}$ and the active $\mathrm{X}$ chromosome (Xa). What determines if a gene is silenced or remains active on the $\mathrm{Xi}$ is not entirely clear. Recent results show that at least one of the escape genes in mice, Jarid1c, contains elements that determine its active status independent of its chromosomal position on the Xi (Li and Carrel, 2008). This indicates that chromosomal sequences or properties of the gene locus modulate the effect that Xist exerts on expression. It is also unknown how Xist represses genes from its primary non-genic binding sites, albeit, evidence for nuclear compartmentalization has been obtained (Heard and Bickmore, 2007; Chow and Heard, 2009). 


\section{Chromosome-wide gene repression and epigenetic modification of the $\mathrm{Xi}$}

In female somatic cells, the $\mathrm{X} i$ forms a stable heterochromatic structure and can be visualized by a variety of staining techniques. Reactivation of genes on the heterochromatic Xi can hardly be achieved unless changes in cell fate are triggered during reprogramming to an early embryonic type (Takagi et al., 1983). Also during the generation of induced pluripotent stem cells from female mouse somatic cells reactivation of the inactive $X$ has been observed (Maherali et al., 2007). Experiments blocking defined epigenetic pathways in somatic cells, including histone deacetylation and DNA methylation, have obtained partial reactivation of the $\mathrm{Xi}$ in a small proportion of cells (Csankovszki et al., 2001). This has led to the conclusion that gene silencing on the $\mathrm{Xi}$ is mediated by a number of epigenetic factors that act together for maintaining the inactive state of the chromosome. The $\mathrm{Xi}$ is subject to several modifications and is enriched for factors that have been associated with silent chromatin (Figure 1). Such a factor is the histone variant macroH2A that is distributed nearly uniformly over the entire $\mathrm{Xi}_{\mathrm{i}}$ in somatic cells (Mietton et al., 2009). This could indicate that once stable inactivation has been achieved genes and non-genic sequences are covered with similar epigenetic modifications on the $\mathrm{Xi}$.

The chromatin composition of the Xi differs markedly from that of other chromosomes in somatic cells. The $\mathrm{Xi}$ is enriched in several histone modifications such as histone $\mathrm{H} 3$ lysine 27 methylation and ubiquitination of histone H2A (Plath et al., 2003; de Napoles et al., 2004; Fang et al., 2004). This is paralleled by the recruitment of Polycomb group complexes (Figure 1a), which have been shown to catalyze these histone modifications (Plath et al., 2004). Furthermore, histone $\mathrm{H} 4$ is hypoacetylated and histone $\mathrm{H} 3$ lysine $4 \mathrm{di}$ - and tri-methylation are strongly reduced on the Xi (Chaumeil et al., 2002). These histone modifications have been generally correlated with gene expression and a reduction of these chromatin modifications on the $\mathrm{Xi}$ could be interpreted as a consequence of its transcriptional inactivity. The function of Polycomb group proteins and histone modifications as well as other components of the $\mathrm{Xi}$, which include the histone variant macroH2A as well as the nuclear scaffold protein SAF-A (Fackelmayer, 2005), remain to be characterized. The current view is that several chromatin features contribute to the maintenance of repression on the Xi (Csankovszki et al., 2001; Hernandez-Munoz et al., 2005).

A genetic screen for epigenetic modifiers in mice has identified a gene that is specifically required for maintenance of gene repression on the Xi (Blewitt et al., 2005). The SMC-hinge domain containing protein SmcHD1 (structural maintenance of chromosomes flexible hinge domain containing 1) has been shown to be required for DNA methylation of Xi-linked gene promoters and silencing on the $\mathrm{Xi}$ in mice (Blewitt et al., 2008). A homozygous mutation of SmcHD1 in female mice does not affect the localization of Xist RNA to the Xi and the a

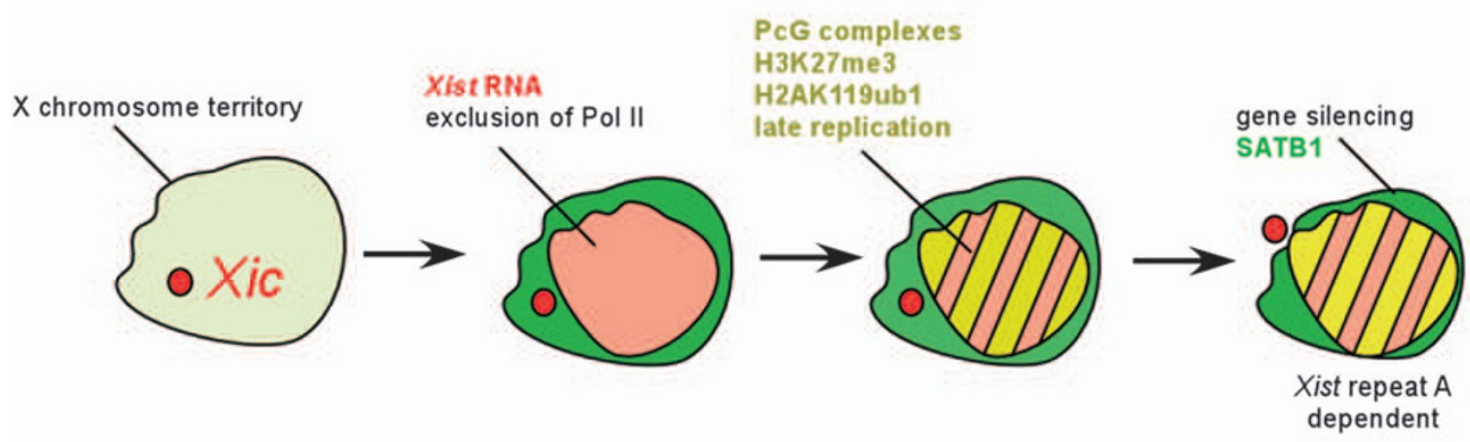

b

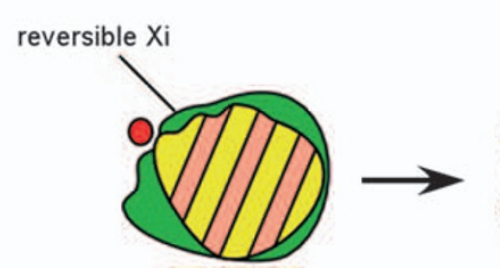

Stabilization of $\mathrm{X}$ inactivation
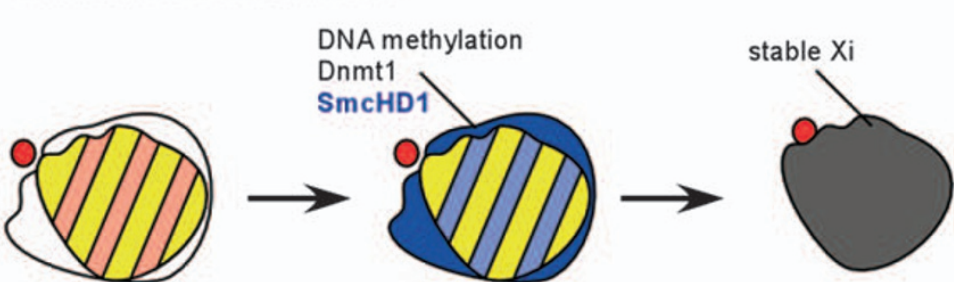

Figure 1 Initiation and maintenance of $X$ inactivation. (a) $X$ inactivation is initiated by expression of Xist RNA. Xist initially overlaps the repeat rich core of the $X$ chromosome territory. RNA polymerase II and components of the transcription machinery are excluded from the Xist domain, whereas genes are located in the periphery of the chromosome territory. Polycomb group (PcG) complexes are recruited to the Xi and mediate tri-methylation of histone $\mathrm{H} 3$ lysine 27 (H3K27me3) and H2A mono-ubiquitination (H2AK119ub1). The chromosome also becomes late replicating in S-phase. Gene repression is then initiated and genes associate with the repressive compartment of the Xist domain on silencing. Initiation of gene repression depends on the repeat A sequence of Xist and on the presence of factors such as SATB1. At this stage chromosome-wide gene repression is entirely reversible and depends on the continued expression of Xist. (b) On cell differentiation the X chromosome attracts additional modifications and X inactivation becomes stable. In differentiated cells, SATB1 expression is lost and Xist loses its ability to induce gene repression. SmcHD1 and DNA methylation are essential for the maintenance of X inactivation. Genes on the $\mathrm{Xi}$ are reactivated in female mouse embryos with a disruption of SmcHD1 or the DNA methyltransferase Dnmt1. In somatic cells further epigenetic modifications contribute to stable silencing leading to $\mathrm{Xi}$ that is largely resistant to reactivation. 
initiation of gene silencing (Blewitt et al., 2008). This shows that SmcHD1 has a role in maintaining the $\mathrm{Xi}$ silent. DNA methylation of promoters on the $\mathrm{Xi}$ has been previously linked to gene repression. A mutation of the DNA methyltransferase Dnmt1 has been shown to lead to a failure in maintaining repression on the $\mathrm{Xi}$ (Sado et al., 2000). These observations strongly argue for a crucial role of DNA methylation in stabilizing the $\mathrm{Xi}$ (Figure 1b). However, blocking of DNA methylation in somatic cells either by using conditional mutagenesis of Dnmt1 or by chemical inhibition does not lead to an efficient reactivation of genes on the $\mathrm{Xi}$ (Csankovszki et al., 2001). This indicates that SmcHD1 and DNA methyltransferases are required for a crucial intermediate step in stabilizing gene repression on the $X$ inactivation. The $\mathrm{Xi}$ is likely further stabilized by other epigenetic changes with progressing differentiation of the cells, which ultimately make it refractory to reactivation. The discovery of SmcHD1 as a novel protein represents an important entry point for deciphering the contribution of DNA methylation to gene silencing in mammals.

\section{The gene silencing mechanism of the non-coding Xist RNA}

$X$ inactivation is normally initiated during early female embryogenesis in mice. The conversion of an active into a transcriptionally silent $X$ chromosome is also observed in differentiating mouse embryonic stem cells. This provides a powerful cell culture system for studying the mechanism of chromosome-wide silencing (Payer and Lee, 2008). $X$ inactivation is triggered by the accumulation of Xist RNA over the future $\mathrm{Xi}$. A conserved sequence on the $5^{\prime}$ of Xist, which has been termed repeat $A$, is required for gene silencing (Wutz et al., 2002). Expression of Xist lacking repeat A does not cause gene repression but results in localization of Xist and recruitment of most chromatin modifications to the Xi (Chaumeil et al., 2006). The repeat A RNA motif is predicted to fold into a stem loop structure, which could function as a binding site for silencing factors (Wutz et al., 2002). Recently, the structure of repeat A RNA has also been experimentally examined (Duszczyk et al., 2008). This study confirmed the first stem loop with the additional finding that the RNA motif might dimerize via a sequence, which was previously suggested to form a second loop. Deletion of repeat $\mathrm{A}$ in mice has also uncovered a function for repression of the antisense Tsix gene within the $X i$, suggesting additional functions for the repeat $A$ region in regulating $X$ inactivation (Hoki et al., 2009).

Chromosome-wide gene repression by Xist is restricted to certain cell types. Normally $X$ inactivation is initiated in cells of the early embryo. In addition, an appropriate cellular context for the initiation of silencing has been shown in specific progenitors in the blood system (Savarese et al., 2006). This was shown by experiments using an inducible expression system for activation of Xist in male mice. XIST expression can also cause gene repression in certain human somatic cell lines with varying extents of chromatin modification (Chow et al., 2007). Recently, it has been shown that Xist can initiate chromosome-wide silencing in tumor cells derived from a mouse lymphoma (Agrelo et al., 2009).
This finding brings up the question if epigenetic pathways normally active during $X$ inactivation in the embryo can be accessed by tumor cells and if these pathways contribute to tumorigenesis.

Using the lymphoma model a component of the Xist silencing pathway has been identified. It was shown that the special AT-rich sequence binding protein SATB1 is required for initiation of gene repression by Xist in lymphoma cells (Agrelo et al., 2009; Brockdorff, 2009). SATB1 is known as a chromatin organizer with important functions for coordinating gene expression in T cells (Alvarez et al., 2000). In T cells, SATB1 forms a cage-like nuclear network that overlaps with the base of chromatin loops in which genes reside (Cai et al., 2006). SATB1 is also expressed in mouse embryonic stem cells at the time when $X$ inactivation is initiated (Agrelo et al., 2009). However, SATB1 is not essential for initiation for $\mathrm{X}$ inactivation as female mice with a disruption of the SATB1 gene can develop (Alvarez et al., 2000). A potential redundancy with other factors such as the closely related gene SATB2 has been offered as an explanation, but this issue remains to be analyzed further. Interestingly, at the initiation of $X$ inactivation SATB1 does not to colocalize with Xist, but is observed in the periphery of the Xist domain (Agrelo et al., 2009), in which it might be associated with genes (Figure 1a). The specific expression pattern of SATB1 suggests that it might change the responsiveness of genes to modulatory signals of gene repression at certain cellular differentiation states. SATB1, thus, might provide a potential entry point for unraveling a developmentally controlled gene regulatory pathway of mammals. It will be interesting to decipher the relationship between Xist repeat $\mathrm{A}$ and SATB1. Both of which are required for the initiation of silencing, yet they do not appear to interact directly.

\section{Regulation of the $\mathrm{X}$ inactivation process}

Before chromosome-wide gene silencing commences and Xist is expressed, a complex process determines if $X$ inactivation should be initiated and ensures that one $X$ chromosome remains active per diploid chromosome set (Figure 2). The elements that identify the presence of an $X$ chromosome in the cell are either located within the Xic or are closely associated with the Xic (Lee et al., 1999; Monkhorst et al., 2008). At the onset of X inactivation, a physical interaction of the two $X$ chromosomes along the Xic regions has been observed (Bacher et al., 2006; Xu et al., 2006). The precise sequences that induce the pairing of the Xic regions within a brief developmental interval are not known. Interestingly, a deletion of all known elements within the Xic has been shown to be compatible with counting of $X$ chromosomes indicating that an additional activator might be present outside the Xic region (Monkhorst et al., 2008). This could involve a novel pairing region, which was recently identified upstream of the Xist gene (Augui et al., 2007). The mechanism of Xic-Xic pairing is poorly understood and it remains unclear how two $X$ chromosomes move and position themselves toward each other in the short developmental interval before Xist upregulation (Figure 2a). Recently, CCCTC-binding factor (CTCF) has been suggested as a crucial factor for pairing ( $\mathrm{Xu}$ et al., 2007). As CTCF is also expressed before and after 

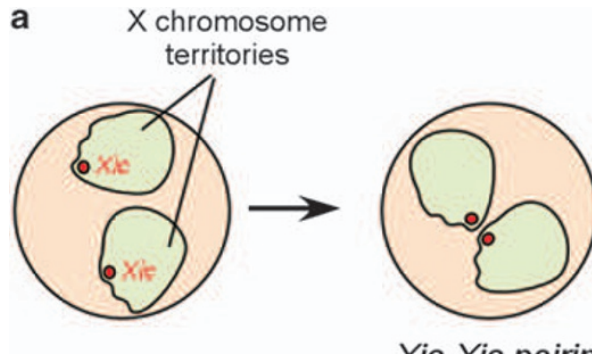

Xic-Xic pairing

b

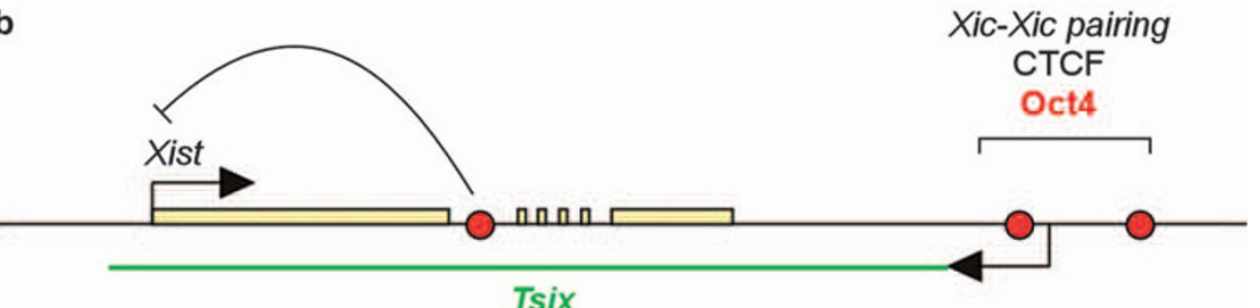

Tsix

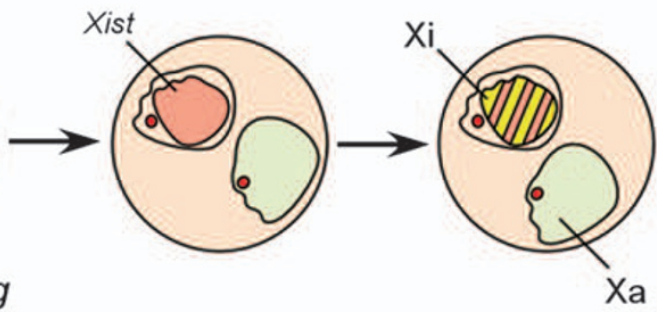

Figure 2 Regulation of X inactivation. (a) X inactivation is initiated in a developmentally controlled manner. All but one $X$ chromosome are inactivated in a diploid cell. Presently, the view is that this is achieved by regulation of Xist expression. Elements for Xist regulation make up the Xic region. At the onset of X inactivation it is believed that trans-chromosomal pairing of the Xic regions triggers Xist expression of one $X$ chromosome. This leads to chromosome-wide gene silencing and formation of an Xi. (b) Elements that regulate Xist expression within the Xic include the non-coding Tsix transcript (green). Tsix is transcribed in antisense orientation to and overlaps the Xist transcription unit, and represses Xist expression. Several Oct4 binding sites (red circles) have been identified within the Xic and mediate repression of Xist in a Tsixdependent and a Tsix-independent mode. Also CTCF has been implicated in Tsix expression and in Xic pairing.

Xic-Xic pairing, it is unlikely the trigger for Xist upregulation but might perform a permissive function.

In mice, Xist expression is repressed by the antisense Tsix RNA (Figure 2b). The transcription unit of Tsix overlaps Xist thereby forming an antisense pair. This antisense Xist-Tsix pairing has provoked thoughts of potential involvement of double-stranded RNA that could be processed by Dicer to small RNAs. Indeed, such small RNAs have been detected in a recent study (Ogawa et al., 2008). However, a comprehensive analysis in embryonic stem cells has shown that a deletion of Dicer has little effect on the $X$ inactivation process suggesting that Dicer has no major role in regulating $X$ inactivation (Kanellopoulou et al., 2009). Deletion of Dicer appears to deregulate the processing of endogenous micro RNAs that leads to a loss of DNA methylation and thereby also affects $X$ inactivation (Nesterova et al., 2008). These data are consistent with indirect effects of Dicer on $X$ inactivation and leave the question of a role of double-stranded RNA in $X$ inactivation open to further investigation.

Recently, the stem cell transcription factor Oct4 has been implicated in the regulation of Xist expression in mice (Navarro et al., 2008; Donohoe et al., 2009). Oct4 has been shown to bind DNA sequences within Xist intron 1 and around the promoter and enhancer sequences of Tsix (Figure 2b). It has been reported that Oct4 mediates repression of Xist in a Tsix-dependent and a Tsix-independent mode. Oct4 expression could thereby limit the upregulation of Xist until $\mathrm{X}$ inactivation is initiated in development. However, Oct4 is also expressed at high levels along with Xist in cell lines other than mouse embryonic stem cells including mouse epiblast-derived stem cells (Navarro and Avner, 2009). Oct4 expression is therefore unlikely the only determinant of Xist upregulation and an additional layer of control might await discovery.

\section{Conservation and divergence of $X$ inactivation across mammals}

Random $X$ inactivation is exclusively observed in placental mammals. In marsupials, the paternally inherited $X$ chromosome is inactivated giving rise to an imprinted pattern of $X$ inactivation. The marsupial imprinted $X$ chromosome shares some features with the $\mathrm{Xi}$ of placental mammals. It lacks histone modifications associated with active chromatin consistent with its repressed state (Koina et al., 2009). A recent study shows that marsupial imprinted $X$ inactivation also involves reactivation of the $X$ chromosome after male meiosis and histone H3 lysine 27 methylation (Mahadevaiah et al., 2009). However, in marsupials Xist is not present. Interestingly, a recent report suggests that Xist is also not required for the initiation of imprinted $X$ inactivation in the extraembryonic tissues in mice (Kalantry et al., 2009). In extraembryonic lineages Xist is required for maintenance of gene repression (Marahrens et al., 1997; Kalantry et al., 2009). This provides evidence for a similarity between imprinted $X$ inactivation in marsupials and in mice. It is noteworthy that there is a clear difference between imprinted and random $X$ inactivation, which is exclusive to placental mammals. $X$ inactivation has recently also been investigated in human preimplantation embryos (van den Berg et al., 2009). Human XIST progressively accumulates on one of the two $X$ chromosomes in female embryos starting at the eight-cell stage. This shows that dosage compensation in preimplantation embryos is more widely conserved among placental mammals. Among placental mammals $\mathrm{X}$ inactivation and Xist appear broadly conserved and $\mathrm{X}$ 
inactivation has been confirmed in a tetraploid mammal (Bacquet et al., 2008). Yet, in certain placental mammals Xist may have been lost. A study reports on a mole species in which Xist might have been lost after complete Y chromosome degeneration and loss of male-female karyotype heteromorphy (Just et al., 2007). This is an interesting example of the evolutionary progression of sex determination and dosage compensation systems within placental mammals.

The Tsix gene, which is vital for Xist regulation during both random and imprinted $X$ inactivation in mice, seems to be not functionally conserved in humans (Migeon et al., 2001). This could indicate that other mechanisms for Xist repression are used by different mammalian species. One such mechanism could be the Tsix-independent repression of Xist by Oct4 (Navarro et al., 2008). It is noteworthy that in mice Xist repression in male cells does not require Tsix (Ohhata et al., 2006). This suggests that also in mice alternative mechanisms for Xist repression are operating. One of these might involve Polycomb function. It has been observed that in male mouse embryonic stem cells Xist is activated when Tsix and Polycomb repressive complex 2 functions are disrupted (Shibata et al., 2008). This suggests that Tsixindependent repression of Xist requires Polycomb repressive complex 2 functions. However, indirect effects because of general chromatin changes in the absence of Polycomb repressive complex 2 cannot be ruled out. The current data suggest that a number of processes might act upstream of Xist to ensure faithful control of $X$ inactivation (for review, see Wutz and Gribnau, 2007). Some of these processes might be emphasized in certain mammals and lost in others. The molecular basis of dosage compensation could therefore show a fair amount of variability among mammalian species.

\section{Conclusions for the mechanism of $X$ inactivation}

Random $X$ inactivation has evolved exclusively in placental mammals. This suggests that the dosage compensation system relies on processes that have mediated gene regulation more broadly in vertebrates. The notable exception is the non-coding Xist RNA and the regulatory sequences of the Xic. These have evolved specifically for the purpose of dosage compensation. There is also evidence that evolution of regulatory elements has not come to a halt and might be ongoing even in present day mammals. Regulation of $X$ inactivation involves chromosomal pairing and antisense repression. Tsix, CTCF, Oct4 and Polycomb complexes have been implicated as molecular players in this process. Chromosome-wide silencing is triggered by the noncoding Xist RNA and appears to be a multistep process. Xist and SATB1 act in the initiation of gene silencing and SmcHD1 and DNA methylation have a crucial role for maintaining repression of the Xi. Also Polycomb group complexes are involved in $\mathrm{X}$ chromosome-wide silencing but their precise function needs to be investigated.

The targets of Xist on the chromosome remain unknown. A role for genomic repeats and non-genic DNA in $X$ inactivation has been suggested by a number of studies. Genes and non-genic chromatin are spatially separated on the Xi. The observation that Xist overlaps the repeat rich center of the $X$ chromosome territory suggests that non-genic chromatin might be the primary target of Xist. This brings up the idea that X inactivation might have co-opted a pre-existing mechanism for repeat element silencing. Genomic repeats comprise the remnants of mobile genetic elements that invaded the genome and subsequently were inactivated. This involves the evolution of host defense mechanisms. Could the inactive $X$ be the result of a controlled engagement of such host defense strategies that is triggered by Xist expression? Long interspersed repetitive elements (LINE) elements have been suggested to perform a function in spreading $X$ inactivation. Recently, $X$ inactivation was compared in a mammalian species in which LINE proliferation has ceased. These data show that LINE amplification is not absolutely required for $X$ inactivation suggesting that also other types of elements could perform a similar role in X inactivation (Cantrell et al., 2009).

Progress in understanding $X$ inactivation has brought up new and more defined questions. The factors that mediate trans-chromosomal interactions during Xic-Xic pairing at the onset of $X$ inactivation need to be identified. Work on the involvement of Oct4 and the developmental timing of $X$ inactivation seems to be a promising route to identify a regulatory network that is intertwined with stem cell biology. A crucial missing piece for understanding the gene silencing pathway is the link between SATB1 and the Xist repeat A. Answering these questions will not only advance our understanding of mammalian dosage compensation but will also provide insights into fundamental nuclear processes for epigenetic regulation in mammals.

\section{Conflict of interest}

The authors declare no conflict of interest.

\section{Acknowledgements}

This work was supported by the IMP through Boehringer Ingelheim and the Austrian Science Fund (FWF). ML was supported by the Austrian genome initiative GEN-AU and AW was supported by a Wellcome Trust Senior Fellowship (grant reference 087530/Z/08/A).

\section{References}

Agrelo R, Souabni A, Novatchkova M, Haslinger C, Leeb M, Komnenovic Vet al. (2009). SATB1 defines the developmental context for gene silencing by Xist in lymphoma and embryonic cells. Dev Cell 16: 507-516.

Alvarez JD, Yasui DH, Niida H, Joh T, Loh DY, KohwiShigematsu $\mathrm{T}$ (2000). The MAR-binding protein SATB1 orchestrates temporal and spatial expression of multiple genes during T-cell development. Genes Dev 14: 521-535.

Augui S, Filion GJ, Huart S, Nora E, Guggiari M, Maresca M et al. (2007). Sensing $X$ chromosome pairs before $X$ inactivation via a novel $\mathrm{X}$-pairing region of the Xic. Science 318: 1632-1636.

Bacher CP, Guggiari M, Brors B, Augui S, Clerc P, Avner P et al. (2006). Transient colocalization of $X$-inactivation centres accompanies the initiation of $\mathrm{X}$ inactivation. Nat Cell Biol 8: 293-299.

Bacquet C, Imamura T, Gonzalez CA, Conejeros I, Kausel G, Neildez-Nguyen TM et al. (2008). Epigenetic processes in a tetraploid mammal. Mamm Genome 19: 439-447. 
Blewitt ME, Gendrel AV, Pang Z, Sparrow DB, Whitelaw N, Craig JM et al. (2008). SmcHD1, containing a structuralmaintenance-of-chromosomes hinge domain, has a critical role in X inactivation. Nat Genet 40: 663-669.

Blewitt ME, Vickaryous NK, Hemley SJ, Ashe A, Bruxner TJ, Preis JI et al. (2005). An N-ethyl-N-nitrosourea screen for genes involved in variegation in the mouse. Proc Natl Acad Sci USA 102: 7629-7634.

Borsani G, Tonlorenzi R, Simmler MC, Dandolo L, Arnaud D, Capra V et al. (1991). Characterization of a murine gene expressed from the inactive $\mathrm{X}$ chromosome. Nature 351: 325-329.

Brockdorff N (2009). SAT in silence. Dev Cell 16: 483-484.

Brockdorff N, Ashworth A, Kay GF, Cooper P, Smith S, McCabe VM et al. (1991). Conservation of position and exclusive expression of mouse Xist from the inactive $X$ chromosome. Nature 351: 329-331.

Brown CJ, Ballabio A, Rupert JL, Lafreniere RG, Grompe M, Tonlorenzi $R$ et al. (1991). A gene from the region of the human $\mathrm{X}$ inactivation centre is expressed exclusively from the inactive $X$ chromosome. Nature 349: 38-44.

Cai S, Lee CC, Kohwi-Shigematsu T (2006). SATB1 packages densely looped, transcriptionally active chromatin for coordinated expression of cytokine genes. Nat Genet 38 : 1278-1288.

Cantrell MA, Carstens BC, Wichman HA (2009). X chromosome inactivation and Xist evolution in a rodent lacking LINE-1 activity. PLoS One 4: e6252.

Chaumeil J, Le Baccon P, Wutz A, Heard E (2006). A novel role for Xist RNA in the formation of a repressive nuclear compartment into which genes are recruited when silenced. Genes Dev 20: 2223-2237.

Chaumeil J, Okamoto I, Guggiari M, Heard E (2002). Integrated kinetics of $\mathrm{X}$ chromosome inactivation in differentiating embryonic stem cells. Cytogenet Genome Res 99: 75-84.

Chow J, Heard E (2009). X inactivation and the complexities of silencing a sex chromosome. Curr Opin Cell Biol 21: 359-366.

Chow JC, Hall LL, Baldry SE, Thorogood NP, Lawrence JB, Brown CJ (2007). Inducible XIST-dependent X-chromosome inactivation in human somatic cells is reversible. Proc Natl Acad Sci USA 104: 10104-10109.

Chureau C, Prissette M, Bourdet A, Barbe V, Cattolico L, Jones L et al. (2002). Comparative sequence analysis of the $X$ inactivation center region in mouse, human, and bovine. Genome Res 12: 894-908.

Clemson CM, Hall LL, Byron M, McNeil J, Lawrence JB (2006). The $\mathrm{X}$ chromosome is organized into a gene-rich outer rim and an internal core containing silenced nongenic sequences. Proc Natl Acad Sci USA 103: 7688-7693.

Csankovszki G, Nagy A, Jaenisch R (2001). Synergism of Xist RNA, DNA methylation, and histone hypoacetylation in maintaining $X$ chromosome inactivation. J Cell Biol 153: 773-784.

de Napoles M, Mermoud JE, Wakao R, Tang YA, Endoh M, Appanah R et al. (2004). Polycomb group proteins Ring1A/B link ubiquitylation of histone $\mathrm{H} 2 \mathrm{~A}$ to heritable gene silencing and X inactivation. Dev Cell 7: 663-676.

Deakin JE, Chaumeil J, Hore TA, Marshall Graves JA (2009). Unravelling the evolutionary origins of $X$ chromosome inactivation in mammals: insights from marsupials and monotremes. Chromosome Res 17: 671-685.

Donohoe ME, Silva SS, Pinter SF, Xu N, Lee JT (2009). The pluripotency factor Oct4 interacts with Ctcf and also controls X-chromosome pairing and counting. Nature 460: 128-132.

Duret L, Chureau C, Samain S, Weissenbach J, Avner P (2006). The Xist RNA gene evolved in eutherians by pseudogenization of a protein-coding gene. Science 312: 1653-1655.

Duszczyk MM, Zanier K, Sattler M (2008). A NMR strategy to unambiguously distinguish nucleic acid hairpin and duplex conformations applied to a Xist RNA A-repeat. Nucleic Acids Res 36: 7068-7077.
Elisaphenko EA, Kolesnikov NN, Shevchenko AI, Rogozin IB, Nesterova TB, Brockdorff $\mathrm{N}$ et al. (2008). A dual origin of the Xist gene from a protein-coding gene and a set of transposable elements. PLoS One 3: e2521.

Fackelmayer FO (2005). A stable proteinaceous structure in the territory of inactive $X$ chromosomes. J Biol Chem 280: 1720-1723.

Fang J, Chen T, Chadwick B, Li E, Zhang Y (2004). Ring1bmediated $\mathrm{H} 2 \mathrm{~A}$ ubiquitination associates with inactive $X$ chromosomes and is involved in initiation of $\mathrm{X}$ inactivation. J Biol Chem 279: 52812-52815.

Graves JA (1996). Mammals that break the rules: genetics of marsupials and monotremes. Annu Rev Genet 30: 233-260.

Heard E, Bickmore W (2007). The ins and outs of gene regulation and chromosome territory organisation. Curr Opin Cell Biol 19: 311-316.

Hernandez-Munoz I, Lund AH, van der Stoop P, Boutsma E, Muijrers I, Verhoeven E et al. (2005). Stable X X chromosome inactivation involves the PRC1 Polycomb complex and requires histone MACROH2A1 and the CULLIN3/SPOP ubiquitin E3 ligase. Proc Natl Acad Sci USA 102: 7635-7640.

Hoki Y, Kimura N, Kanbayashi M, Amakawa Y, Ohhata T, Sasaki H et al. (2009). A proximal conserved repeat in the Xist gene is essential as a genomic element for X-inactivation in mouse. Development 136: 139-146.

Just W, Baumstark A, Suss A, Graphodatsky A, Rens W, Schafer $\mathrm{N}$ et al. (2007). Ellobius lutescens: sex determination and sex chromosome. Sex Dev 1: 211-221.

Kalantry S, Purushothaman S, Bowen RB, Starmer J, Magnuson $\mathrm{T}$ (2009). Evidence of Xist RNA-independent initiation of mouse imprinted $\mathrm{X}$-chromosome inactivation. Nature 460: 647-651.

Kanellopoulou C, Muljo SA, Dimitrov SD, Chen X, Colin C, Plath $\mathrm{K}$ et al. (2009). X chromosome inactivation in the absence of Dicer. Proc Natl Acad Sci USA 106: 1122-1127.

Koina E, Chaumeil J, Greaves IK, Tremethick DJ, Graves JA (2009). Specific patterns of histone marks accompany $X$ chromosome inactivation in a marsupial. Chromosome Res 17: $115-126$.

Lee JT, Lu N, Han Y (1999). Genetic analysis of the mouse X inactivation center defines an $80-\mathrm{kb}$ multifunction domain. Proc Natl Acad Sci USA 96: 3836-3841.

Li N, Carrel L (2008). Escape from X chromosome inactivation is an intrinsic property of the Jarid1c locus. Proc Natl Acad Sci USA 105: 17055-17060.

Mahadevaiah SK, Royo H, Vandeberg JL, McCarrey JR, Mackay $S$, Turner JM (2009). Key features of the $X$ inactivation process are conserved between marsupials and eutherians. Curr Biol 19: 1478-1484.

Maherali N, Sridharan R, Xie W, Utikal J, Eminli S, Arnold K et al. (2007). Directly reprogrammed fibroblasts show global epigenetic remodeling and widespread tissue contribution. Cell Stem Cell 1: 55-70.

Marahrens Y, Panning B, Dausman J, Strauss W, Jaenisch R (1997). Xist-deficient mice are defective in dosage compensation but not spermatogenesis. Genes Dev 11: 156-166.

Mietton F, Sengupta AK, Molla A, Picchi G, Barral S, Heliot L et al. (2009). Weak but uniform enrichment of the histone variant macroH2A1 along the inactive X chromosome. Mol Cell Biol 29: 150-156.

Migeon BR, Chowdhury AK, Dunston JA, McIntosh I (2001). Identification of TSIX, encoding an RNA antisense to human XIST, reveals differences from its murine counterpart: implications for X inactivation. Am J Hum Genet 69: 951-960.

Monkhorst K, Jonkers I, Rentmeester E, Grosveld F, Gribnau J (2008). X inactivation counting and choice is a stochastic process: evidence for involvement of an X-linked activator. Cell 132: 410-421.

Navarro P, Avner P (2009). When X-inactivation meets pluripotency: an intimate rendezvous. FEBS Lett 583 1721-1727. 
Navarro P, Chambers I, Karwacki-Neisius V, Chureau C, Morey C, Rougeulle C et al. (2008). Molecular coupling of Xist regulation and pluripotency. Science 321: 1693-1695.

Nesterova TB, Popova BC, Cobb BS, Norton S, Senner CE, Tang YA et al. (2008). Dicer regulates Xist promoter methylation in ES cells indirectly through transcriptional control of Dnmt3a. Epigenetics Chromatin 1: 2.

Nesterova TB, Slobodyanyuk SY, Elisaphenko EA, Shevchenko AI, Johnston C, Pavlova ME et al. (2001). Characterization of the genomic Xist locus in rodents reveals conservation of overall gene structure and tandem repeats but rapid evolution of unique sequence. Genome Res 11: 833-849.

Ogawa Y, Sun BK, Lee JT (2008). Intersection of the RNA interference and X-inactivation pathways. Science 320: 1336-1341.

Ohhata T, Hoki Y, Sasaki H, Sado T (2006). Tsix-deficient X chromosome does not undergo inactivation in the embryonic lineage in males: implications for Tsix-independent silencing of Xist. Cytogenet Genome Res 113: 345-349.

Payer B, Lee JT (2008). X chromosome dosage compensation: how mammals keep the balance. Annu Rev Genet 42: 733-772.

Plath K, Fang J, Mlynarczyk-Evans SK, Cao R, Worringer KA, Wang $\mathrm{H}$ et al. (2003). Role of histone H3 lysine 27 methylation in $\mathrm{X}$ inactivation. Science 300: 131-135.

Plath K, Talbot D, Hamer KM, Otte AP, Yang TP, Jaenisch R et al. (2004). Developmentally regulated alterations in Polycomb repressive complex 1 proteins on the inactive $X$ chromosome. J Cell Biol 167: 1025-1035.
Sado T, Fenner MH, Tan SS, Tam P, Shioda T, Li E (2000). X inactivation in the mouse embryo deficient for Dnmt1: distinct effect of hypomethylation on imprinted and random X inactivation. Dev Biol 225: 294-303.

Savarese F, Flahndorfer K, Jaenisch R, Busslinger M, Wutz A (2006). Hematopoietic precursor cells transiently reestablish permissiveness for X inactivation. Mol Cell Biol 26: 7167-7177.

Shibata S, Yokota T, Wutz A (2008). Synergy of Eed and Tsix in the repression of Xist gene and $\mathrm{X}$-chromosome inactivation. EMBO J 27: 1816-1826.

Takagi N, Yoshida MA, Sugawara O, Sasaki M (1983). Reversal of $\mathrm{X}$-inactivation in female mouse somatic cells hybridized with murine teratocarcinoma stem cells in vitro. Cell 34: 1053-1062.

van den Berg IM, Laven JS, Stevens M, Jonkers I, Galjaard RJ, Gribnau J et al. (2009). X chromosome inactivation is initiated in human preimplantation embryos. Am J Hum Genet 84: 771-779.

Wutz A, Gribnau J (2007). X inactivation Xplained. Curr Opin Genet Dev 17: 387-393.

Wutz A, Rasmussen TP, Jaenisch R (2002). Chromosomal silencing and localization are mediated by different domains of Xist RNA. Nat Genet 30: 167-174.

Xu N, Donohoe ME, Silva SS, Lee JT (2007). Evidence that homologous X-chromosome pairing requires transcription and Ctcf protein. Nat Genet 39: 1390-1396.

$\mathrm{Xu} \mathrm{N}$, Tsai CL, Lee JT (2006). Transient homologous chromosome pairing marks the onset of $\mathrm{X}$ inactivation. Science 311: 1149-1152. 